\title{
Development of foaming vaginal tablets with clotrimazole. Part I. Optimization of the formulation using design of experiments approach
}

\author{
Edit LÁSZLÓ, Ioan TOMUTA, Sorin E. LEUCUTA \\ Department of Pharmaceutical Technology and Biopharmacy, Faculty of Pharmacy, \\ "Iuliu Hatieganu" University of Medicine and Pharmacy, Cluj-Napoca, Romania
}

\begin{abstract}
Objectives. The aim of this study was to optimize the formulation of certain immediate release foaming vaginal tablets, with fast vaginal disintegration (part I), fallowing their time stability (part II).

Material and methods. Modde optimizing software and a Box-Bhenken experimental design was used to establish an optimal formula that would provide maximum "in vitro" behaviour advantages, including stability during preservation; and the improvement of the foaming effect. There were prepared 15 formulations of foaming vaginal tablets in order to choose the optimal formula.

Outcomes. The main factor, with influence over all the studied parameters, is the percentage of the effervescent mixture in the formulation. The excess of citric acid has a main role in the assurance of local $\mathrm{pH}$; in the improvement of the flowing properties of the powder mixtures before compression; and in the improvement of the effervescent process, having, on the other hand, an effect of decreasing the stability of tablets and increasing their humidity adsorption. Sodium lauryl sulphate, at the chosen concentration levels (0.5-1.5\%), did not influence the dependent variables, it only produced a stronger resistance of the foam. The optimal formula of a foaming vaginal tablet with an optimal stability during preservation must contain $0.5 \%$ sodium lauryl sulphate, while the effervescent mixture must contain a percentage of $24 \%$ excess of citric acid, and it must represent $44 \%$ of the total amount of excipients.

Conclusions. The experimental determinations of the optimal formula were close to the theoretical values predicted by the program, this certifying the validity of the optimization and the conclusion draw after analysis the experimental design.
\end{abstract}

Keywords: foaming tablets, vaginal tablets, clotrimazole, experimental design, Box-Bhenken

\section{INTRODUCTION}

Foaming vaginal pharmaceutical dosage forms allow the uniform spread of the doses on the whole mucosal surface of the vagina, and assures a rapid disintegration of the pharmaceutical form, associated by a lack of flowing from the site of application (1,2). Being conceived for a mucosal route, these tablets must carry out some standards $(2,3)$ concerning especially their form which has to be conformed to an easily applicable device without producing vaginal lesions; and concerning their dissolution capacity, which has to assure the dissolution in a very low liquid 
volume ( 2 $\mathrm{ml}$ ), associated with a diffusion and a spread between all the vaginal mucosal velocities.

Another problem is how to assure their stability in time.

Concerning the medicinal substance, we used clotrimazole as model drug, a well-tolerated $(1,6,7)$ imidazole derivate with clinically proved local antimycotic, antibacterial, and antitrychomoniazic effect $(4,5)$ The class of antimycotics was chosed regarding the very prevalent mycotic vaginal pathology. A number of $75 \%$ of women suffer during their life one acute vaginal candidose, $40-50 \%$ of women suffer 2-3 episodes; a number of $10 \%$ of sexually mature women have suffered from vaginal candidose during their premenstrual period. $10-20 \%$ of contaminated women suffer from a chronic form of candidose with 4 acute episodes during a year, and a percent of $20 \%$ of women are asymptomatic carriers of vaginal Candida albicans (6-15).

The aim of this study was to optimize the formulation of immediate release foaming vaginal tablet formulation with fast vaginal disintegration using a Box-Bhenken experimental design and Modde optimizing software. There were analysed 15 responses, concerning the properties of the powder mixtures, the properties of the tablets, considering that the studied responses are the most important characteristics of a foaming vaginal tablet.

\section{MATERIALS AND METHODS}

\section{Materials}

Clotrimazole (Beijing Double Crane Pharmaceutical Co. Ltd-China); citric acid (Chimopar); sodium hydrogen carbonate (Chimopar); anhydrous sodium carbonate (Chimopar); sodium laurylsulphate (Loba Feinchemie-Austria); Ludipress Direct Compression Excipient (BASF-Germany); Methocel E15-LV-EP, Low Viscosity (Colorcon LTD U.K); Aerosil (S\&D Chemicals UK); magnesium stearate (Union Derivan-Spain); anhydrous sodium sulphate (Chimopar)

\section{Apparatus}

Analytical balance Analytical Plus (Ohaus SUA); Sieve analyzer set DIN (VEB MLW, Germany); MTM Owen (Hungary); Erweka powder mixer with infinite movement RM (Germany); Erweka SVM devices for powder density studies (Germany); Erweka GTD devices (Germany) for powder flowing time study; Exocentric tablet press Korsch EK-0 Germany; Monsanto device (Italy), for tablet's mechanical resistance study; Erweka apparatus for friability study; a special device to study the volume and the resistance of the generated foam; Humidity Balance Ohaus MB 45 (SUA); Mettler-Toledo Quatro Type MP 225 pH-meter, Switzerland; Ultra sounds bath Ultrasonics-Transsonic 700 Elma; HPLC Agilent 1100 with UV detection; column HPLC Zorbax SB-C8.

\section{Software and experimental design}

To perform the study, a BoxBhenken experimental design $3^{3}$ with three factors and three levels was used. Experimental design, coefficient calculation, statistic parameters calculation and evaluation of the quality of fitting were performed with Modde 12.0 (Sartorius Stedim Data Analytics AB, Sweden). The independent variables (formulation factors considered the most influents in the case of foaming vaginal tablets) and the levels of variation are presented in table 1.

The dependent variables are presented in table 2 .

\section{Methods}

Formulation and preparation of the foaming vaginal tablets

After consulting the literature (16-20) we used the following ingredients to prepare foaming vaginal tablets: effervescent mixture (15-65\%) with alkaline component sodium hydrogen carbonate associated with anhydrous sodium carbonate $(10 \%$ from the alkaline amount for a better stability) and as acid component citric acid (in excess to obtain an optimum $\mathrm{pH}$ - between 4.2 and 6 after foaming), clotrimazole $10 \%$ for a $100 \mathrm{mg}$ dose in an $1 \mathrm{~g}$ weight tablet; foaming agent sodium laurylsulphate (0.5-1.5\%); Ludipress as diluent; Methocel E15 2\% as binder, magnesium stearate $1 \%$ as lubricant and Aerosil $1 \%$ as foam resistance enhancer.

The foaming vaginal tablets were obtained by direct compression in normal thermo-hygrometrical conditions, using a Korsch EK 0 excentric press, equipped with droplet shaped die set punch. The powders were individually dried until a $0.5 \%$ humidity before

TABLE 1. Independent variables (formulation factors)

\begin{tabular}{|l|c|c|c|c|}
\hline \multirow{2}{*}{ Formulation variables } & & \multicolumn{3}{|c|}{ Levels } \\
\cline { 2 - 5 } & Symbol & $\mathbf{- 1}$ & $\mathbf{0}$ & $\mathbf{+ 1}$ \\
\hline Sodium laurylsulphate percent & $\mathrm{X}_{1}$ & 0.5 & 1 & 1.5 \\
\hline Effervescent mixture percent & $\mathrm{X}_{2}$ & 25 & 45 & 65 \\
\hline Citric acid excess (\%) & $\mathrm{X}_{3}$ & 5 & 15 & 25 \\
\hline
\end{tabular}


TABLE 2. The matrix of the experimental design

\begin{tabular}{|c|c|c|c|c|}
\hline Exp. Name & Run Order & $\mathbf{x}_{\mathbf{1}}$ & $\mathbf{X}_{\mathbf{2}}$ & $\mathbf{X}_{\mathbf{3}}$ \\
\hline N1 & 7 & 0.5 & 25 & 15 \\
\hline N2 & 1 & 1.5 & 25 & 15 \\
\hline N3 & 10 & 0.5 & 65 & 15 \\
\hline N4 & 13 & 1.5 & 65 & 15 \\
\hline N5 & 11 & 0.5 & 45 & 5 \\
\hline N6 & 12 & 1.5 & 45 & 5 \\
\hline N7 & 3 & 0.5 & 45 & 25 \\
\hline N8 & 8 & 1.5 & 45 & 25 \\
\hline N9 & 5 & 1 & 25 & 5 \\
\hline N10 & 2 & 1 & 65 & 5 \\
\hline N11 & 4 & 1 & 25 & 25 \\
\hline N12 & 6 & 1 & 65 & 25 \\
\hline N13 & 15 & 1 & 45 & 15 \\
\hline N14 & 14 & 1 & 45 & 15 \\
\hline N15 & 9 & 1 & 45 & 15 \\
\hline
\end{tabular}

$X_{1}$ - sodium laurylsulphate percent, $X_{2}$ - effervescent mixture percent, $X_{3}$ - percent of citric acid excess in the effervescent mixture

blending. There were obtained 15 formulations of droplet shaped tablets with $2.5 \mathrm{~cm}$ length; $1.2 \mathrm{~cm}$ maximum diameter and weights between 0.897 and 1.064 grams. The resulted tablets followed the pharmacopeial requirements concerning the weight and content uniformity. The preparation and stability studies in normal thermohygrometrical conditions can assure us that the optimal formulation obtained will show maximal resistance to the environmental conditions during production and preservation.

Determination of the dependent variables (responses) In order to obtain the optimal formula, we studied a number of 29 responses, these being considered by us as the most important characteristics of a foaming vaginal tablet. There were determined: flowability indexes of powder mixtures (flowing time, Carr index and Hausner ratio) using Erweka apparatus; mechanical resistance of the tablets using Monsanto apparatus; friability of the tablets using Erweka friability apparatus; the volume and resistance of the foam resulted after disintegration in $2 \mathrm{ml}$ simulated vaginal fluid (SVF) at $37^{\circ} \mathrm{C}$, using a device described by the literature (2) composed by a calibrated glass test tube suspended from a ring stand in a constant temperature bath $37^{\circ} \mathrm{C}$ and a $1 \mathrm{~g}$ rubber cylinder suspended by a thread, that could be gently lowered onto the surface of the foam, when the foam attained the maximal possible volume and we can determine the time until the foam will be collapsed by the $1 \mathrm{~g}$ weight ; foaming time of the tablets in $5 \mathrm{ml} \mathrm{SVF}$ at $37^{\circ} \mathrm{C}$; the mass of carbon dioxide loosed during 20 minute foaming in $30 \mathrm{ml} \mathrm{SVF}$ at $37^{\circ} \mathrm{C}$, using a gravimetric method described by the literature (21), the $\mathrm{pH}$ generated in the following mediums $\left(30 \mathrm{ml}\right.$ at $\left.37^{\circ} \mathrm{C}\right)$ : distilled water, SVF pH 4.2; acetate buffer $\mathrm{pH} 5.5$, to determine the $\mathrm{pH}$ generated by the tablet itself, but also to observe if the foaming vaginal tablet formulations have a capacity to change an eventually local pH buffer effect. An important indicator of the stability was the humidity of the powder mixtures and of the tablets, determined by using a humidity Ohaus MB 45 (USA) balance. 
TABLE 3. Dependent variables (responses) determined after preparation

\begin{tabular}{|c|l|c|}
\hline Number & \multicolumn{1}{|c|}{ Responses } & Symbols \\
\hline 1 & Carr Index for powder mixtures (\%) & $\mathrm{Y}_{1}$ \\
\hline 2 & Hausner Ratio for powder mixtures & $\mathrm{Y}_{2}$ \\
\hline 3 & Flowing time of the powder mixtures (min) & $\mathrm{Y}_{3}$ \\
\hline 4 & Mechanical resistance of the tablets (kg) & $\mathrm{Y}_{4}$ \\
\hline 5 & Friability of the tablets (\%) & $\mathrm{Y}_{5}$ \\
\hline 6 & Foaming time (min) & $\mathrm{Y}_{6}$ \\
\hline 7 & Maximal volume of the foam (ml) & $\mathrm{Y}_{7}$ \\
\hline 8 & Resistance of the foam (min) & $\mathrm{Y}_{8}$ \\
\hline 9 & Weight of CO2 loosed by 20 minute foaming (g) & $\mathrm{Y}_{9}$ \\
\hline 10 & pH generated in 30 ml distilled water & $\mathrm{Y}_{10}$ \\
\hline 11 & pH generated in 30 ml (FVS) pH 4.2 & $\mathrm{Y}_{11}$ \\
\hline 12 & pH generated in 30 ml acetate buffer, $\mathrm{pH} \mathrm{5.5}$ & $\mathrm{Y}_{12}$ \\
\hline
\end{tabular}

Most of the determinations were repeated after 1 and 3 months on the tablets kept in normal thermohygrometrical conditions in the presence of anhydrous sodium sulphate, to conclude the stability of the formulations. The described responses and the symbols used for interpretation of the data are represented in table 3 .

\section{RESULTS AND DISCUSSIONS}

Results for the dependent variables (responses) determination The results obtained for the dependent variables determinations are represented in table 4.

The results showed that there are great differences between the formulations, concerning the friability, a parameter for which we can discover excessively great values for some formulations (ex. N2 6.3\%). Concerning the mechanical resistance of the tablets, the values obtained are distributed on a large scale (from $5.5 \mathrm{~kg}$ to $14 \mathrm{~kg}$ ). There were obtained very good values for flowing time of powder mixtures and for $\mathrm{pH}$ responses for almost all the formulations. The time of foaming showed good values, the greatest part of the results being below 10 minutes (the time established for the disintegration of a foaming vaginal tablet) (2). The volume and resistance of the foam are responses which shoes a great dependence on the formulation factors (independent variables).

As we can see, there are little differences between the humidity of powder mixtures before compression and the humidity of the tablets resulted, but the initial humidity of the powders was in all cases below 0,5\% after drying. The conclusion is that during the compression process a humidity absorption phenomenon takes place. The results showed that the amount of humidity absorbed is independent on the formulation and depends on the environmental termo-hygrometrical conditions (22).

Fitting of the experimental data with the model

Fitting of experimental data was realized with the Modde software, using the Partial Least Squares (PLS)

TABLE 4. Matrix of the responses obtained for the determinations immediate after preparation

\begin{tabular}{|c|c|c|c|c|c|c|c|c|c|c|c|c|}
\hline Exp Name & $\mathbf{Y}_{\mathbf{1}}$ & $\mathbf{Y}_{\mathbf{2}}$ & $\mathbf{Y}_{\mathbf{3}}$ & $\mathbf{Y}_{\mathbf{4}}$ & $\mathbf{Y}_{\mathbf{5}}$ & $\mathbf{Y}_{\mathbf{6}}$ & $\mathbf{Y}_{\mathbf{7}}$ & $\mathbf{Y}_{\mathbf{8}}$ & $\mathbf{Y}_{9}$ & $\mathbf{Y}_{10}$ & $\mathbf{Y}_{11}$ & $\mathbf{Y}_{\mathbf{1 2}}$ \\
\hline $\mathrm{N} 1$ & 17.65 & 1.21 & 40 & 14 & 3.5 & 4.5 & 8 & 1.5 & 0.23 & 5.76 & 5.10 & 5.49 \\
\hline $\mathrm{N} 2$ & 11.11 & 1.13 & 44 & 12 & 6.3 & 13 & 5 & 0.083 & 0.221 & 5.85 & 5.00 & 5.5 \\
\hline $\mathrm{N} 3$ & 16.13 & 1.19 & 103 & 9 & 0.82 & 4 & 25 & 5 & 0.417 & 4.99 & 4.59 & 5.37 \\
\hline N4 & 20.63 & 1.26 & 92 & 7.5 & 0.91 & 10 & 25 & 6.5 & 0.4 & 5.02 & 4.52 & 5.39 \\
\hline N5 & 18.18 & 1.22 & 78 & 7.5 & 0.95 & 2.5 & 21 & 7.5 & 0.26 & 5.91 & 5.2 & 5.56 \\
\hline N6 & 21.21 & 1.27 & 69 & 8 & 0.83 & 7.5 & 16.5 & 25 & 0.257 & 6.00 & 5.23 & 5.77 \\
\hline N7 & 12.5 & 1.14 & 83 & 9 & 0.77 & 3.5 & 12 & 7 & 0.3 & 4.8 & 4.45 & 5.23 \\
\hline N8 & 12.5 & 1.14 & 65 & 5.5 & 0.98 & 7.5 & 12 & 20 & 0.28 & 4.85 & 4.49 & 5.13 \\
\hline N9 & 12.12 & 1.14 & 48 & 14 & 5.5 & 7 & 8.5 & 0.33 & 0.2 & 6.46 & 5.26 & 5.45 \\
\hline N10 & 20 & 1.25 & 110 & 9 & 0.47 & 6.7 & 28 & 5.5 & 0.355 & 5.8 & 4.97 & 5.45 \\
\hline N11 & 9.68 & 1.11 & 52 & 9.5 & 6.8 & 12 & 7 & 0.33 & 0.241 & 5.35 & 4.82 & 5.09 \\
\hline N12 & 20 & 1.25 & 97 & 5.5 & 0.45 & 7 & 23 & 6 & 0.425 & 4.24 & 4.22 & 5.2 \\
\hline N13 & 16.67 & 1.2 & 75 & 10 & 0.52 & 5.7 & 15 & 13.3 & 0.279 & 5.24 & 4.69 & 5.2 \\
\hline N14 & 20 & 1.25 & 79 & 9.5 & 0.83 & 6.5 & 15.5 & 15.5 & 0.27 & 5.31 & 4.75 & 5.3 \\
\hline N15 & 18.18 & 1.22 & 71 & 10 & 0.92 & 4.9 & 14.5 & 15 & 0.275 & 5.28 & 4.72 & 5.28 \\
\hline
\end{tabular}

$Y_{1}-$ Carr Index (\%), $Y_{2}-$ Hausner Ratio, $Y_{3}-$ flowing time (min), $Y_{4}-$ mechanical resistance $(k g), Y_{5}-$ friability (\%), $Y_{6}-$ foaming time $(\mathrm{min}), Y_{7}$ - foam maximal volume $(\mathrm{ml}), \mathrm{Y}_{8}$ - resistance of the foam (min before collapse), $Y_{9}$ - weight of loosed $\mathrm{CO}_{2}(\mathrm{~g}), \mathrm{Y}_{10}-\mathrm{pH}$ water, $\mathrm{Y}_{11}-\mathrm{pH}$ in SVF, $\mathrm{Y}_{12}-\mathrm{pH}$ in buffer 


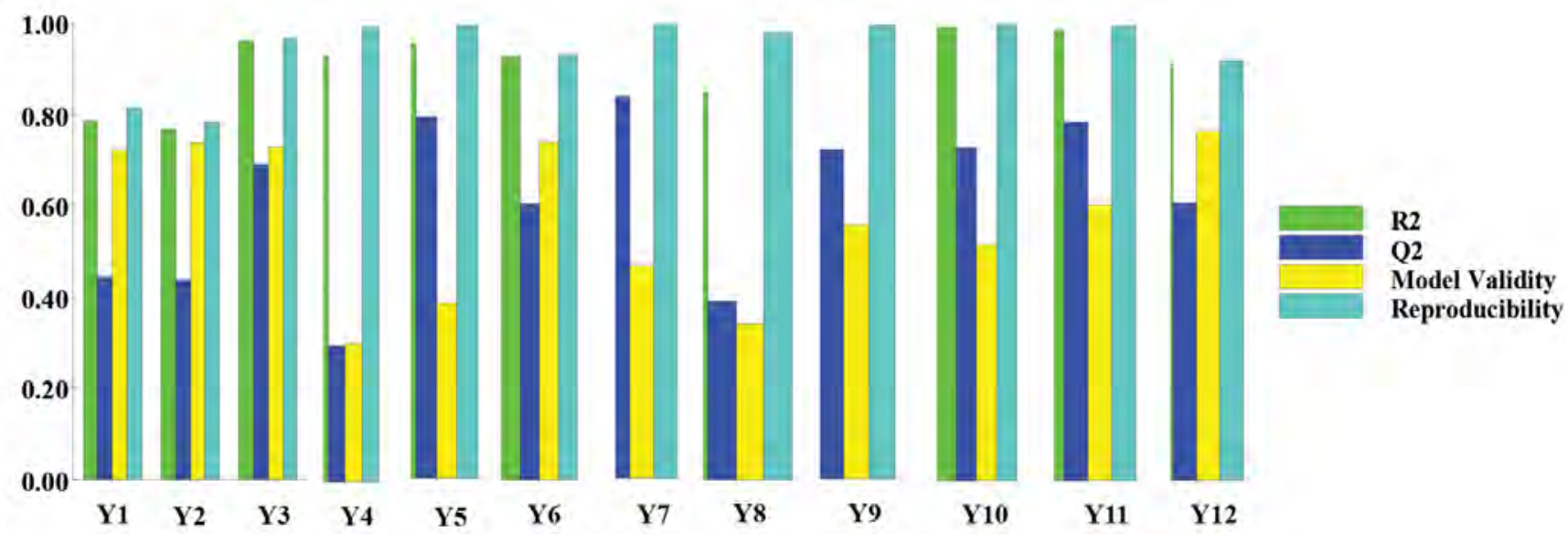

FIGURE 1. Histogram representing the fitting of the data after preparation, with the model

$: Y_{1}$ - Carr Index (\%), $Y_{2}-$ Hausner Ratio, $Y_{3}$ - flowing time (min), $Y_{4}-$ mechanical resistance (kg), $Y_{5}-$ friability (\%), $Y_{6}-$ foaming time (min), $Y_{7}-$ foam maximal volume $(\mathrm{ml}), \mathrm{Y}_{8}$ - resistance of the foam (min before collapse), $Y_{9}$ - weight of loosed $\mathrm{CO}_{2}(\mathrm{~g}), \mathrm{Y}_{10}-\mathrm{pH}$ water, $\mathrm{Y}_{11}-\mathrm{pH}$ in SVF, $\mathrm{Y}_{12}-\mathrm{pH}$ in buffer

method. The results obtained are represented by histograms in fig. 1 .

The ANOVA variance analysis test showed good results for most of the studied responses $(p<0.05$ for the model and $p>0.05$ for the error). We obtained anyway some deviations for the following responses: $Y_{13}$ (mechanical resistance after 1 month) with values of $p$ being 0.067 for the model and 0.108 for the error; $Y_{26}$ (humidity of powder mixtures before compression) with values of $p$ being 0.03 for the model and 0.022 for error; and $\mathrm{Y}_{27}$ (humidity of the tablets after compression) with values of $p$ being 0.124 for the model and 0.025 for error.

Considering that there were 29 responses studied, we can say that the fitting of the data with the model was good. Another method for the evaluation of the fitting is by drawing the dependence curves between the obtained values and the values predicted by the model. Using this method, the best fittings obtained for $Y_{3}$ - flowing time ( $\min ), Y_{6}$ - foaming time $(\min ), Y_{7}-$ foam maximal volume $(\mathrm{ml}), \mathrm{Y}_{9}-$ weight of loosed $\mathrm{CO}_{2}$ by foaming (g), $\mathrm{Y}_{10}-\mathrm{pH}$ generated in distilled water, and $\mathrm{Y}_{11}-\mathrm{pH}$ generated in SVF (after preparation) (data not show).

The influence of formulation factors on powder flow properties Graphs representing the influence of formulation factors on Carr's $\left(\mathrm{Y}_{1}\right)$ are illustrated in Fig. 2.a. Carr's index increases with increasing the percentage of effervescent mixture $\left(X_{2}\right)$ and decreases with the increase of the excess citric acid $\left(\mathrm{X}_{3}\right)$, being independent of the percentage of sodium lauryl sulphate. Graphs representing the influence of formulation factors on Hausner ratio $\left(\mathrm{Y}_{2}\right)$ are illustrated in Fig. 2.b. Hausner ratio increases with increasing the percentage of effervescent mixture $\left(X_{2}\right)$ and decreases with the increase of the excess citric acid $\left(X_{3}\right)$, being independent of the percentage of sodium lauryl sulphate, the results being consistent with those obtained for Carr's index. Graphs representing the influence of formulation factors on flowing time of powders are illustrated in Figure 2.c. Flowing time increases with increasing the percentage of effervescent mixture $\left(X_{2}\right)$, so with 
the decrease in the percentage of diluent Ludipress, and is independent of the other formulation variables chosen.

The results obtained for the study of the flowing time show very good flow for all formulations studied (Hausner ratio between 11.11 and 21.21; Carr's index between 1.11 and 1.26), and in terms of its variation depending on formulation factors, the results show that the effervescent mixture makes the flow difficult, probably due to interactions between mixture components, which can lead to an enhancement of powder humidity during processing. Citric acid has a very good flow, so the excess of citric acid facilitates the flow. So, a good flow is achieved with a small amount of effervescent mixture (which corresponds to a higher ratio of diluent Ludipress), and a higher percentage of excess citric acid.
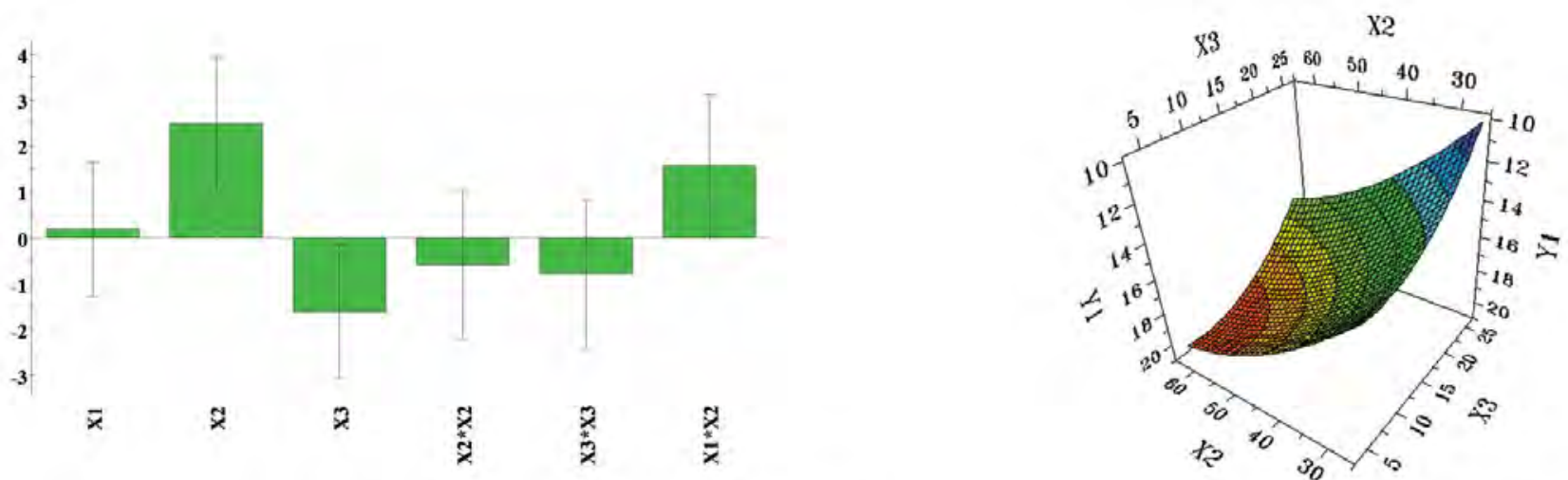

a
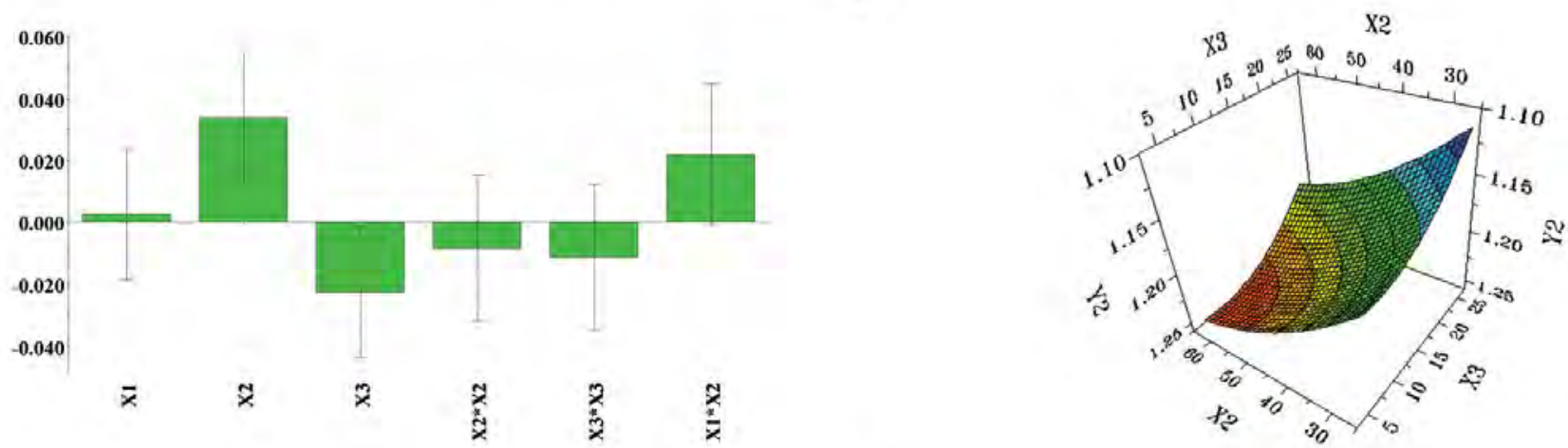

b
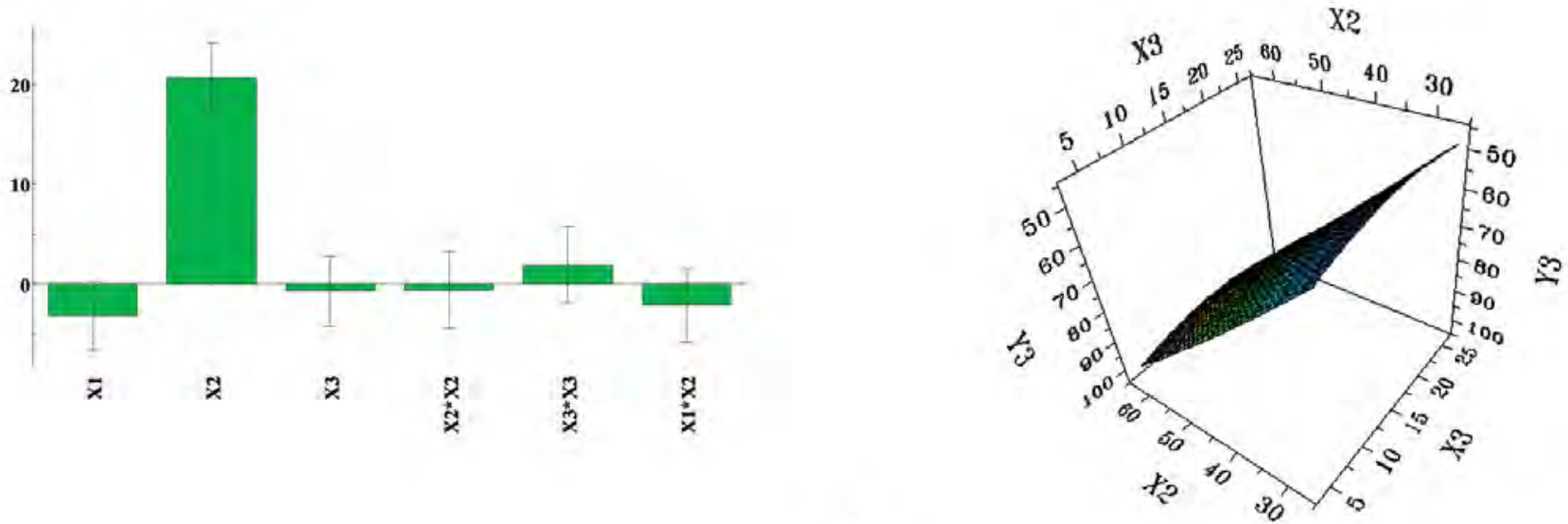

FIGURE 2. The influence of formulation factors on powder flow

a - Carr Index, Y1; b - Hausner Ratio, Y2 ; c - flowing time, Y3

$\mathrm{X} 1$ - percentage of sodium lauryl sulphate, $\mathrm{X} 2$ - percentage of effervescent mixture, $\mathrm{X} 3$ - percentage of excess of citric acid in the effervescent mixture 
The influence of formulation factors on tablets properties immediate after preparation

Graphs representing the influence of formulation factors on

mechanical resistance of the tablets are illustrated in Fig. 3a. The results show that the mechanical resistance of effervescent tablets does not depend on the formulation variables chosen. This is understandable because the mechanical resistance depends mainly on the compression force, which has changed from one formulation to another. However, it was not introduced in the experimental design, because it was not monitored, So, in this study the mechanical resistance and the compression force were variables that the experimental design was unable to control. However, there is a tendency of mechanical resistance decrease with increasing the percentage of all the variables chosen, so with the decrease of Ludipress percentage, and the graph has a minimum at $65 \%$ effervescent mixture and 1.5\% sodium lauryl sulphate. We can thus draw the conclusion that an increase of Ludipress percentage may increase mechanical resistance. This result is understandable, given the good compressibility and compactibility properties of this excipient (16).

Graphs representing the influence of formulation factors on the tablets friability $\left(\mathrm{Y}_{5}\right)$ are illustrated in Fig. 3.b. Although for friability the results are poorly fit with the model and there is a great variability of data (from improper values $5-6 \%$ to rather small values $0.45 \%)$, the friability depending generally on other factors than those chosen for the study, yet it may be observed that friability decreases with increasing the percentage of effervescent mixture $\left(X_{2}\right)$, the chart registering a minimum at $65 \%$ effervescent mixture. Also, at $25 \%$ effervescent mixture, most formulations were inadequate in terms of friability, although they had a high mechanical resistance (from 9.5 to 14). These results suggest that the effervescent mixture reduces the friability, probably by the interactions of its components, and that there is probably an optimal ratio between the diluent and the effervescent mixture that allows these interactions and thereby obtaining tablets with appropriate friability, but this phenomenon may have negative effects on foaming and stability in time.

Graphs representing the influence of formulation factors on foaming time $\left(\mathrm{Y}_{6}\right)$ are illustrated in Fig. 3.c. Foaming time increases with increasing the percentage of sodium lauryl sulphate $\left(\mathrm{X}_{1}\right)$ and decreases with increasing the percentage of effervescent mixture $\left(X_{2}\right)$, but for this formulation variable $\left(\mathrm{X}_{2}\right)$, a nonlinear effect is observed. Regarding the concentration of sodium lauryl sulphate, some data in the literature state that the foaming slows down the effervescence speed, due to changes in fluid properties in which the disintegration takes place $(16,17,18)$, so the higher the concentration of sodium lauryl sulphate, the higher the duration of disaggregation time will be, but this effect may be due to the fact that with increasing the percentage of sodium lauryl sulphate a higher compression force is needed, leading to tablets that have a slow disaggregation through foaming. Regarding $\mathrm{X}_{2}$ variable (percentage of effervescent mixture), its growth decreases foaming time, because if 

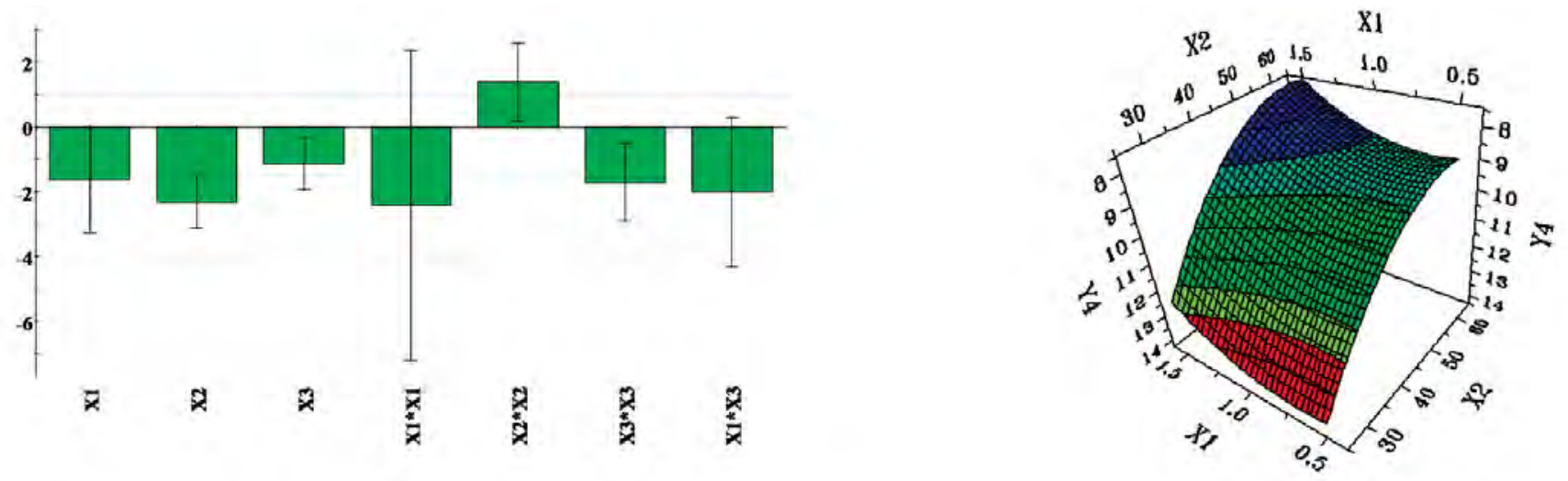

a
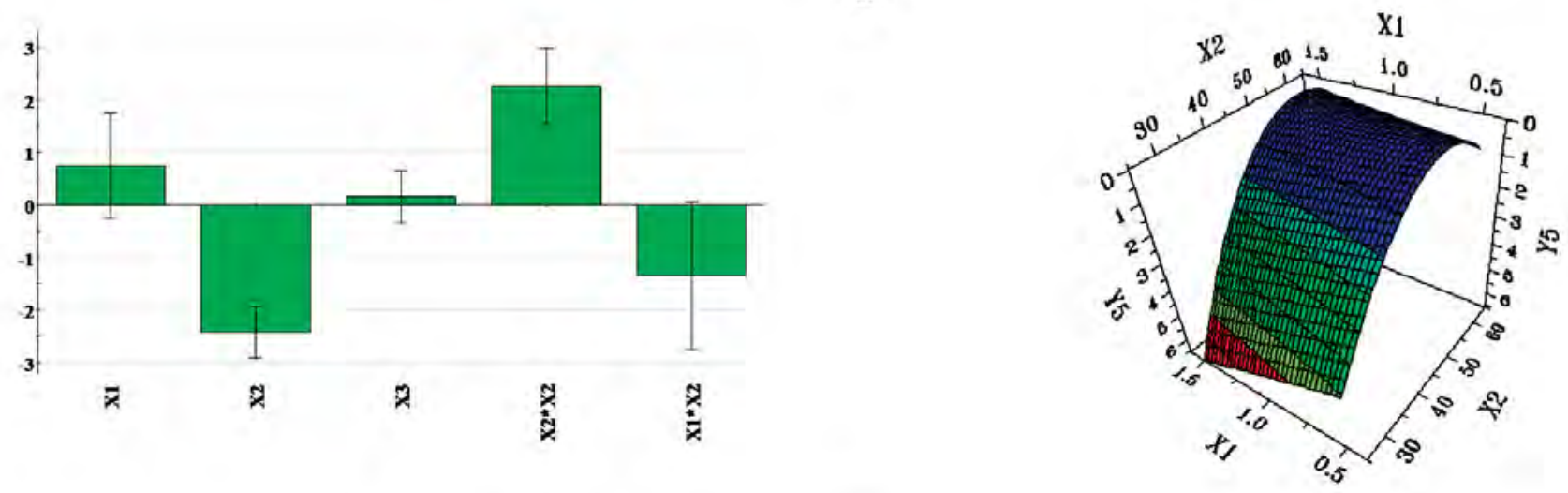

b
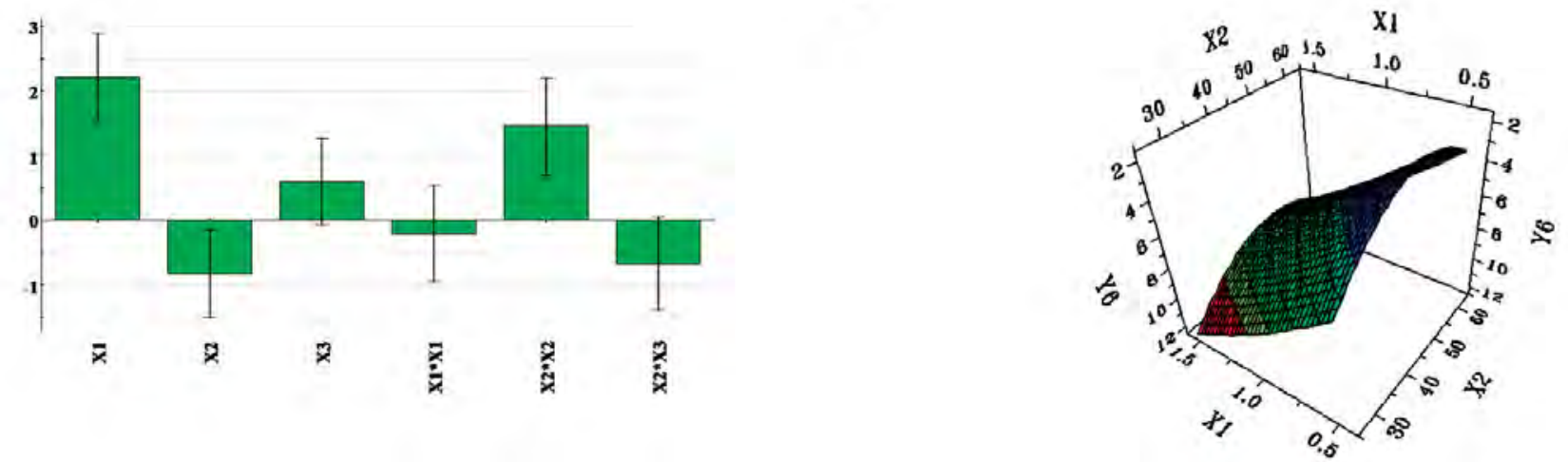

C
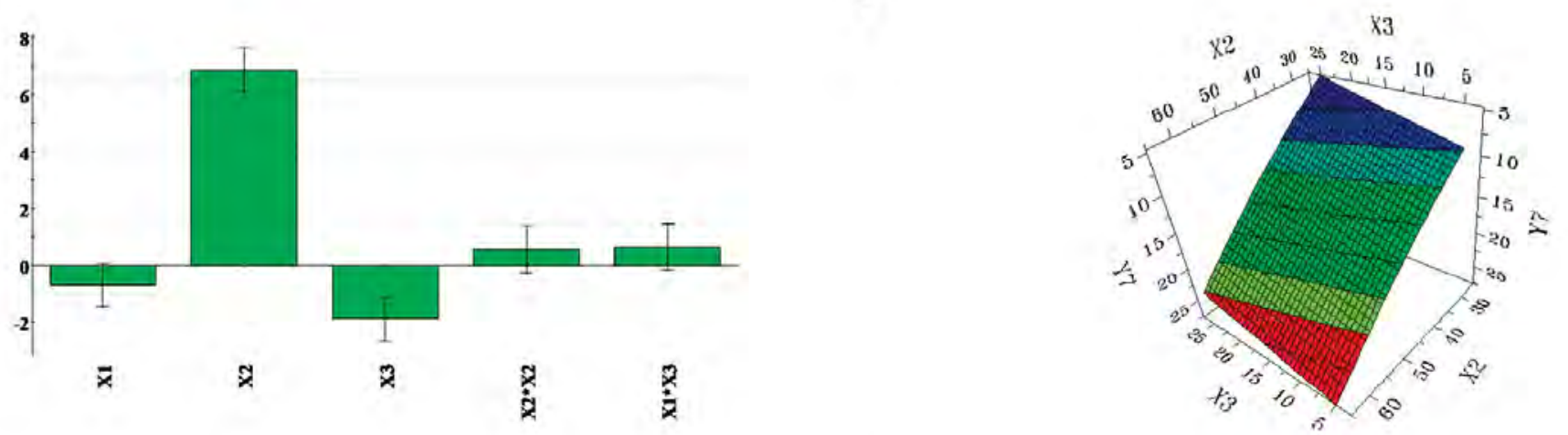

d 

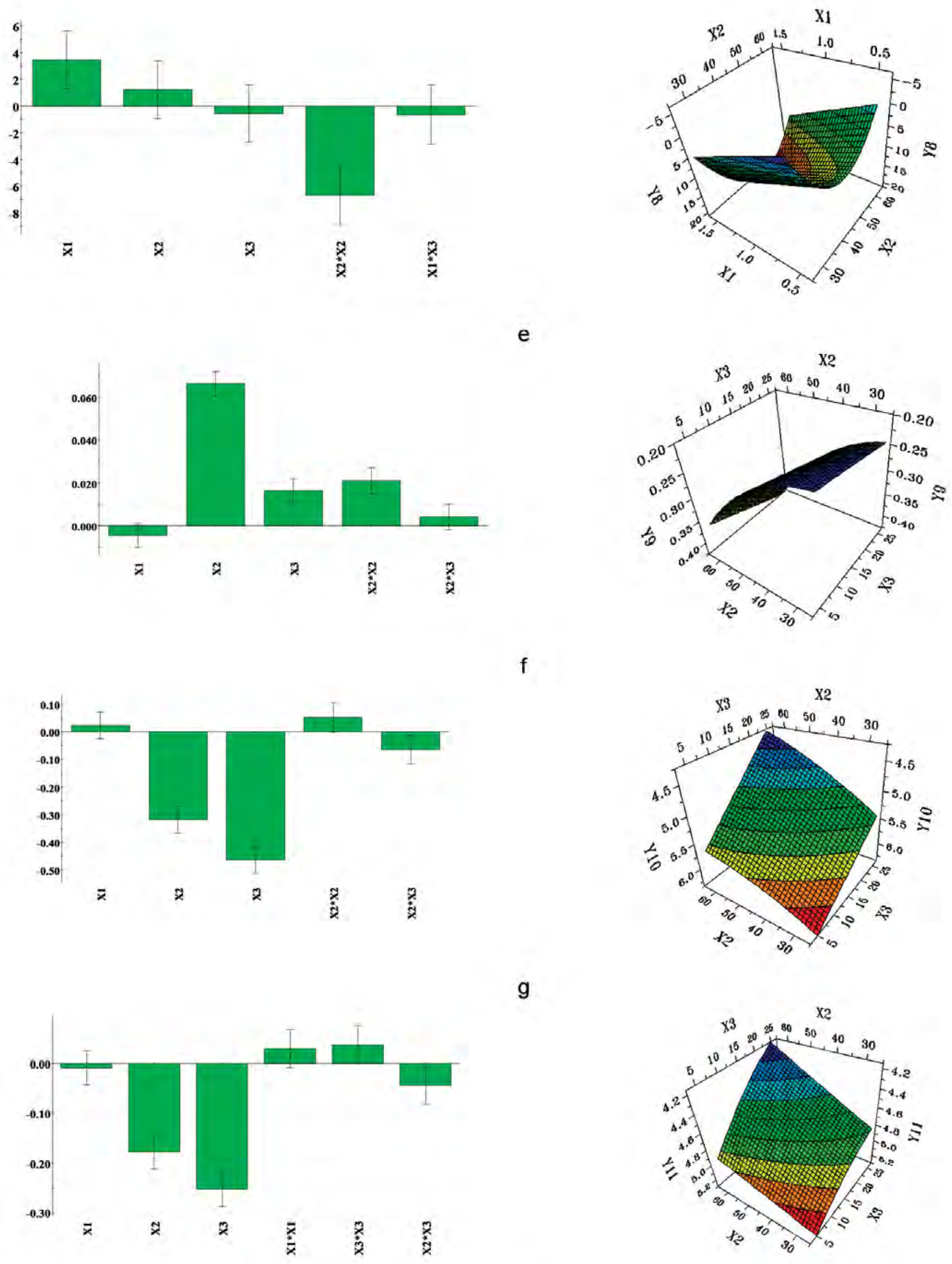


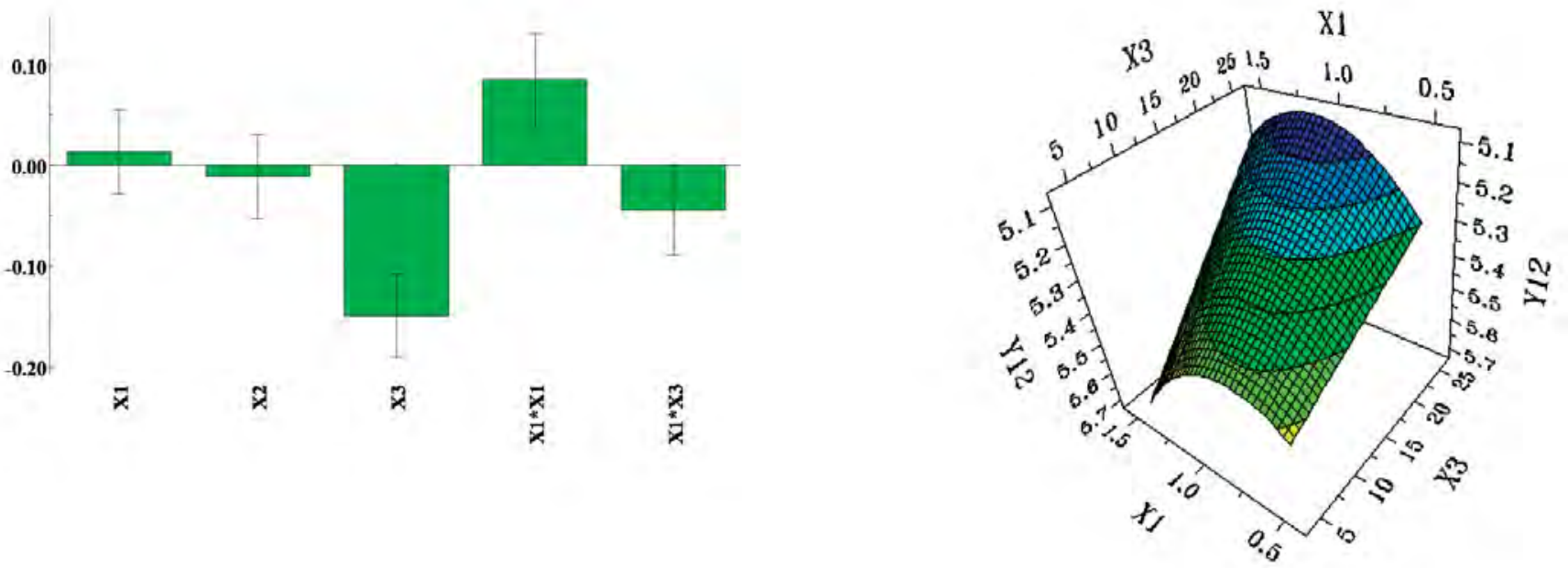

FIGURE 3. The influence of formulation factors on tablets properties

$\mathrm{a}$ - mechanical resistance, $\mathrm{Y} 4 ; \mathrm{b}$ - tablets friability, $\mathrm{Y} 5$; $\mathrm{c}$ - flowing time, $\mathrm{Y} 6$; $d$ - foam volume, $\mathrm{Y} 7 \mathrm{e}$ - foam resistance, $\mathrm{Y} 8$; $f$ - amount of $\mathrm{CO} 2$ released, $\mathrm{Y} 9 ; \mathrm{g}-\mathrm{pH}$ generated in water, $\mathrm{Y} 10 ; \mathrm{h}-\mathrm{pH}$ generated in $\mathrm{SVF}, \mathrm{Y} 11 ; \mathrm{i}-\mathrm{pH}$ generated in acetate buffer, $\mathrm{Y} 12$

$\mathrm{X} 1$ - percentage of sodium lauryl sulphate, $\mathrm{X} 2$ - percentage of effervescent mixture, $\mathrm{X} 3$ - percentage of excess of citric acid in the effervescent mixture

the amount of effervescent mixture is greater, the decomposition will be faster, with a broader interaction between the effervescent mixture components, a more abundant effervescence and a faster consumption of these components. For values greater than $45 \%$ effervescent mixture (value for which the chart has a minimum), the foaming time does not decrease with increasing the percentage of effervescent mixture, probably because over this threshold value the amount of effervescent mixture is so great that time between decomposition and consumption of the effervescent reaction is longer than for the concentration of $45 \%$, and in this case we must also take into account the dissolution time of the effervescent mixture components in the small volume of vaginal fluid. Another explanation is that a high percentage of effervescent mixture needs a too high compression force, leading to an interaction between components during compression and a strengthening of the tablet core, slowing down the final stage of disaggregation $(1,17,19)$.

Graphs representing the influence of formulation factors on maximal volume of foam $\left(\mathrm{Y}_{7}\right)$ are illustrated in Fig. 3.d. From the graphical representations it may be concluded that the volume of the foam formed in the disaggregation process depends mostly on the percentage of effervescent mixture $\left(\mathrm{X}_{2}\right)$ and increases with its amount increase. The volume of foam depends very little on the excess citric acid $\left(\mathrm{X}_{3}\right)$, decreasing with its increase and does not depend on the percentage of sodium lauryl sulphate $\left(X_{1}\right)$. This behaviour may be explained by the fact that to achieve the maximal volume of foam, several competing processes take place simultaneously: foam formation, foam maintenance and foam breaking. Depending on the speed of these processes, the final volume of foam will result. If the foam formation speed and its maintenance is greater than its breaking, the volume increases; if the foam formation speed is smaller than the foam breaking speed, the foam does not increase in time, but remains at a minimum volume, or does not form at all. The results suggest that when the foam formation process is predominant, it depends only on the effervescent mixture. Perhaps increasing the percentage of effervescent mixture increases formation speed and maintenance of foam; foam breaking has a constant speed that depends on the studied environment (SVF) and is independent of the percentage of effervescent mixture and the percentage of sodium lauryl sulphate. We can say that there is no need to increase the percentage of sodium lauryl sulphate to increase the foam volume; there is probably a threshold concentration of sodium lauryl sulphate above which the foam breaking has a constant speed, and this concentration is below the minimum concentration used in the experience design, taking into 
consideration the small volume of the environment used for the experiment.

Graphs representing the influence of formulation factors on foam resistance $\left(\mathrm{Y}_{8}\right)$ are illustrated in Fig. 3.e. Although for foam volume we obtained an independent behaviour of the sodium lauryl sulphate percentage, foam resistance increases with the increase of sodium lauryl sulphate percentage $\left(X_{1}\right)$, but also with the increase of effervescent mixture percentage $\left(X_{2}\right)$; for the latter, the dependence is nonlinear. These results may be explained by the fact that a higher percentage of sodium lauryl sulphate produces a higher density foam which, because of the low surface tension of the foam spheres $(16,17)$, withstands the mechanical action of external forces, this effect being greater with increasing the percentage of effervescent mixture that generates the foam spheres. The three-dimensional graph shows a maximal concentration at $45 \%$ effervescent mixture, suggesting that an increase of the percentage of effervescent mixture over $45 \%$ will not increase the foam resistance, but will decrease it, probably due to the fact that above this threshold value the release of carbone dioxide resulted in the effervescence is high, leading to larger foam spheres that break faster $(20,21)$.

Graphs representing the influence of formulation factors on the amount of $\mathrm{CO}_{2}$ released after foaming $\left(\mathrm{Y}_{9}\right)$ are illustrated in Fig. 3.f. The amount of carbon dioxide released after effervescence increases with the increase of effervescence mixture percentage $\left(X_{2}\right)$ and citric acid excess $\left(X_{3}\right)$. This behaviour is understandable $(19,22)$, because if effervescent mixture percentage is higher, the stoichiometric quantity of carbone dioxide resulting from the reaction of effervescence will be higher. Citric acid excess leads to the acidification of the environment and to the decrease of carbon dioxide solubility, which promotes its release.

Graphs representing the influence of formulation factors on $\mathrm{pH}$ values generated in water $\left(\mathrm{Y}_{10}\right)$ after tablet disintegration in water are shown in Fig. 3.f. Regarding the $\mathrm{pH}$ produced by effervescent tablets disintegration, it may be observed that it decreases with the increase of the percentage of effervescent mixture $\left(X_{2}\right)$ and with the increase of citric acid excess $\left(X_{3}\right)$. Since all formulations contain a certain excess of citric acid, the higher the effervescent mixture percentage, the higher the amount of citric acid excess and the amount of citric acid in each tablet is, leading to a lower $\mathrm{pH}$ after effervescence. Another factor involved is carbon dioxide released after the effervescence reaction, which may also acidify the environment studied $(19,21)$.

Graphs representing the influence of formulation factors on $\mathrm{pH}$ values recorded after tablet disintegration in simulated vaginal fluid (SVF) $\left(\mathrm{Y}_{11}\right)$ are illustrated in Fig. 3.g. The results for $\mathrm{pH}$ values in simulated vaginal fluid show a similar dependence with the one obtained for water, but the values of final $\mathrm{pH}$ are lower because the $\mathrm{pH}$ of the environment studied is lower (SVF $\mathrm{pH}=4.2$ ). It can be stated that all prepared formulations develop, in simulated vaginal fluid, a suitable $\mathrm{pH}$ for this route of administration of the tablets ( $\mathrm{pH}$ between 4.22 and 5.26). One can observe that in simulated vaginal fluid, effervescent tablets cause a slight increase of $\mathrm{pH}$, but the values are in the physiological range $(20,21)$. 
Graphs representing the influence of formulation factors on $\mathrm{pH}$ values recorded after tablet disintegration in acetate buffer ( $\mathrm{pH}$ 5.5) $\left(\mathrm{Y}_{12}\right)$ are illustrated in Fig. 3.h.The graphs representing the variation of $\mathrm{pH}$ in acetate buffer $\mathrm{pH} 5.5$ show that its change, depending on the formulation, is due only to citric acid excess $\left(\mathrm{X}_{3}\right)$ and is independent of the percentage of effervescent mixture $\left(X_{2}\right)$. We can drag the conclusion that an excess of citric acid in the effervescent couple lowers the possible buffering capacity, while the effervescent mixture itself cannot cause such an effect, which can be demonstrated by the fact that in most cases the $\mathrm{pH}$ decreases and only in one case it increases slightly $(\mathrm{pH}=5.77$ for N6 formulation).

\section{Optimal formula determination}

The domains and theoretical levels chosen for the dependent variables and the experimental responses obtained for the optimal formula are represented in table 5 .

The optimal domains for the levels of dependent variables were chosen considering that we need an equilibrium between an easy preparation; quality assurance; time stability; easy disintegration; energetic foaming with keeping of the local mucosal environmental conditions. Based on the chosen levels for the dependent variables, the optimizing program recommended the following levels for the formulation factors, of an intravaginal foaming tablet: $0.5 \%$ sodium laurylsulphate $\left(\mathrm{X}_{1}\right) ; 44 \%$ total amount of effervescent mixture in the formulation $\left(\mathrm{X}_{2}\right)$; with $24 \%$ excess of citric acid in the effervescent mixture $\left(\mathrm{X}_{3}\right)$. The optimal formula presented the following responses (properties): Carr Index for powder blend: 12.9\%; Hausner Ratio for powder blend: 1.17; flowing time of powder blend: 80 minutes; mechanical resistance of the tablet: $8.5 \mathrm{~kg}$; tablet friability: $0.8 \%$; foaming time: 3.5 minutes; foam maximal volume: $18 \mathrm{ml}$; resistance of the foam: 6.5 minutes before collapse; $\mathrm{CO}_{2}$ weight loss: $0.29 \mathrm{~g} ; \mathrm{pH}$ generated in distilled water: 4.95; $\mathrm{pH}$ generated in SVF: 4.5; $\mathrm{pH}$

TABLE 5. The optimal formula, based on chosen domains; the experimental responses obtained for the prepared optimal formula

\begin{tabular}{|c|c|c|c|}
\hline $\begin{array}{c}\text { Dependent } \\
\text { variables }\end{array}$ & Chosen domain & $\begin{array}{c}\text { Theoretical values } \\
\text { predicted } \\
\text { by software }\end{array}$ & $\begin{array}{c}\text { Practical values } \\
\text { obtained } \\
\text { after preparation }\end{array}$ \\
\hline Y1 & $<20$ & 14.4 & 12.9 \\
\hline Y2 & $50-80$ & 1.17 & 1.17 \\
\hline Y3 & $5.5-9 \downarrow$ & 77 & 80 \\
\hline Y4 & $0.5-0.99 \downarrow$ & 8.64 & 8.5 \\
\hline Y5 & $5-10 \downarrow$ & 0.69 & 0.8 \\
\hline Y6 & $15-20$ & 3.17 & 3.5 \\
\hline Y7 & 5 & 12.43 & 18 \\
\hline Y8 & $0.25-0.35 \uparrow$ & 10.3 & 0.5 \\
\hline Y9 & $4.5-5$ & 0.29 & 4.95 \\
\hline Y10 & $4.2-4.7$ & 4.78 & 4.5 \\
\hline Y11 & $5.1-5.3$ & 4.57 & 5.28 \\
\hline Y12 & 5.33 & \\
\hline
\end{tabular}

$Y_{1}$ - Carr Index (\%), $Y_{2}-$ Hausner Ratio, $Y_{3}-$ flowing time $(\mathrm{min}), Y_{4}$-mechanical resistance $(\mathrm{kg}), Y_{5}-$ friability (\%), $Y_{6}$ - foaming time $(\mathrm{min}), Y_{7}$ - foam maximal volume $(\mathrm{ml}), Y_{8}$ - resistance of the foam (min before collapse), $Y_{9}$ - weight of loosed $\mathrm{CO}_{2}(\mathrm{~g}), \mathrm{Y}_{10}-\mathrm{pH}$ water, $\mathrm{Y}_{11}-\mathrm{pH}$ in SVF, $\mathrm{Y}_{12}-\mathrm{pH}$ in buffer. 
generated in $\mathrm{pH}=5.5$ acetate buffer

The theoretical values predicted by the optimizing program for the optimal formula, were very close to the practical values obtained by preparation and analysis of the recommended formula; these attesting the validity of optimization based on Modde optimizing software.

\section{CONCLUSIONS}

Fifteen formulations of foaming vaginal fast release tablets for local antimycotic action were prepared, in order to choose the optimal formula with the Box Bhenken optimization design based on the Modde optimization software. The main factor involved in the behaviour of tablets immediately after preparation is the percentage of effervescent mixture. There is a very small influence of sodium lauryl sulphate on the dependent variables. The concentration of sodium lauryl sulphate was considered to be decisive only for two properties: foaming time and foam resistance. An interesting result is that the volume of foam does not depend on the percentage of sodium lauryl sulphate (for the chosen concentration levels). The optimal formula of a foaming vaginal tablet, obtained with the Box-Bhenken design, must contain $0.5 \%$ sodium lauryl sulphate, while the effervescent mixture must contain a percentage of $24 \%$ citric acid excess, and it must represent $44 \%$ of the total amount of excipients. The experimental determinations on the optimal formula were close to the theoretical values predicted by the program, this attesting the validity of the optimization, based on the Box-Bhenken experimental design.

Conflict of interest: none declared Financial support: none declared

Formulations. Pharmaceutical Technology 2001;25(9):14-24.

2000;50(3): 337-343

9. Doering PL, Santiago TM. Drugs for treatment of vulvovaginal candidiasis, efficacy of agents and regimens. DICP. 1990;24(11):1078-1083.

10. Zhou X, Li T, Fan S, Zhu Y, Liu X, Guo X, Liang $Y$. The efficacy and safety of clotrimazole vaginal tablet vs. oral fluconazole in treating severe vulvovaginal candidiasis. Mycoses. 2016;59(7):419-428.

11. Sawyer PR, Brogden RN, Pinder RM, Speight TM, Avery. Clotrimazole: A review of its antifungal activity and therapeutic efficacy. Drugs. 1975;9(6):424-447.

12. Lut VD. Clinical microbicide research: An overview. Tropical Medicine and Internatioanl Health. 2004;9(12):12901296.

13. Lians MD. Pathologie d'origine mycosique; Moniteur Internat; Infectiologie, Tome 5, Paris, France 2002, p.335-345.

14. Hernandez Molina JM, Liosa J, Martinez Brocal A, Ventosa A. In vitro activity of cloconazole, sulconazole, butoconazole, isoconazole, fenticonazole, and five other antifungal agents against clinical isolates of Candida albicans and Candida spp. Mycopathologia 1992;118(1):15-21.

15. Sharma G, Jain S, Tiwary AK, Kaur G. Once daily bioadhesive vaginal clotrimazole tablets: Design and evaluation. Acta Pharm. 2006;56(3):337-345.

16. Garg S, Tambwekar KR, Vermani K, Garg A Kaul CL, Zaneveld JD. Compendium of Pharmaceutical Excipients for Vaginal
17. Pandey KH, Mahalingan K: Effervescent bioadhesive vaginal tablet of metronidazole for bacterial vaginosis - design and in-vitro evaluation. Int J Pharm Sci \& Res. 2014;5(9): 3746-3751.

18. Wewalka G, Stary A, Bosse B, Duerr HE, vaginal suppositories in the treatment of bacterial vaginosis. Dermatology. 2002;204 Suppl 1:79-85.

19. Wang L, Tang X. A novel ketoconazole bioadhesive effervescent tablet for vaginal delivery: design, in vitro and 'in vivo' evaluation. Int J Pharm. 2008;350(1-2):181187.

20. Du B, Shao C. Terbinafine hydrochloride vaginal effervescent tablet and preparation method thereof. Patent PAT:CN101543479, Application: CN20081015601 on 24 Mar 2008.

21. Yanze MF, Duru C, Jacob M., Gasc F. The carbon dioximeter: A device for quantifying the carbon dioxide released from effervescent pharmaceuticals. J. Pharm. Belg. 2000;55(2):53-56.

22. Horhota ST, Burgio J, Lonski L, Rhodes CT. Effect of storage at specified temperature and humidity on properties of three directly compressible tablet formulations. J Pharm Sci. 1976;65(12):1746-1749. Reimer K. Efficacy of povidone-iodine 